\title{
Microstructure and mechanical behaviour of friction stir processed AZ91-D magnesium alloy - optimization of process parameters by using the Taguchi method
}

\author{
P. Kumar ${ }^{1}$, L. Thakur ${ }^{2}$, N. Bhadouria ${ }^{3 *}$, S. Dixit $^{4}$ \\ ${ }^{1}$ Technical Secretariat of Chairman-cum-Managing Director, Northern Coalfields Limited, Singrauli, India \\ ${ }^{2}$ Mechanical Engineering Department, National Institute of Technology, Kurukshetra, India \\ ${ }^{3}$ Department of Mechanical and Energy Engineering, Purdue University, USA \\ ${ }^{4}$ Department of Materials and Contracts, NMDC Iron and Steel Plant, Jagdalpur, India
}

Received 5 June 2018, received in revised form 5 March 2019, accepted 5 March 2019

\begin{abstract}
In the present research, friction stir processing (FSP) of as-cast AZ91-D Mg-alloy has been done to improve its ultimate tensile strength (UTS). Taguchi's L-9 orthogonal array was used to optimize the process parameters for improving the UTS of AZ91-D parent material $(\mathrm{PM})$. The optimum levels of process parameters were found to be $1000 \mathrm{rpm}, 50 \mathrm{~mm} \mathrm{~min} \mathrm{~m}^{-1}$ and 6 passes for the rotational tool speed, transverse speed and a number of passes of FSP, respectively. As per ANOVA results, the number of passes has the highest statistical effect of about $41.3 \%$ on UTS.

Additionally, the micro-hardness tests were conducted to confirm the process optimization. The FSPed material with optimized parameters showed an enhancement of 24.56 and $77.5 \%$ in UTS and micro-hardness as compared to PM respectively. The grain size of FSPed material was observed to be 6.88 times lesser than PM. Microstructure evaluation of optimized FSPed material also confirmed the uniform dispersion of $\beta$-phase $\left(\mathrm{Mg}_{17} \mathrm{Al}_{12}\right)$ resulting in improved properties.
\end{abstract}

K e y w o r d s: magnesium, friction stir processing, Taguchi, tensile strength, micro-hardness, dynamic recrystallization

\section{Introduction}

As the lightest constructional material, magnesium alloys are of paramount importance for aerospace and automobile industries due to their high stiffness to weight ratio, dimensional stability, high recyclability and low carbon emissions. On the other hand, properties like poor corrosion resistance, poor formability at room temperature, low wear resistance and low strength at elevated temperature overshadow its advantages [1]. To enhance the mechanical properties of magnesium alloys different techniques based on severe plastic deformation (SPD) have been used to produce fine grains. Some of the conventional techniques to produce fine grains are equal channel angular extrusion (ECAE), equal channel angular pressing (ECAP), high-pressure torsion (HPT), accumulating roll bond- ing $(A R B)$, repetitive corrugation/straightening and twist extrusion. Samaee et al. [2] found that after two ECAP passes, the ductility of the Al-alloy decreased from the original value. However, on further ECAP processing up to six passes, the strength and ductility increased which was attributed to fine grain structure. Similarly, Sadawy et al. [3] obtained fine-grained bronze alloy and also showed an improvement in its corrosion resistance by ECAP method. Fattah et al. [4] and Gashti et al. [5] obtained ultrafine-grained microstructure of Al-alloy by ARB and concluded the decrease in grain size with an increase in a number of cycles of ARB. Saito et al. [6] confirmed the achievement of ultra-fine grain structure as well as significant increase in strength of material after several cycles of $\mathrm{ARB}$ of $\mathrm{Al}$ alloy, Al-Mg alloy and Ti-added interstitial free steel.

\footnotetext{
*Corresponding author: tel.: +1-(317)-702-3538; e-mail address: neharikabhadouria201@gmail.com
} 
Table 1. Chemical composition (wt.\%) of AZ91-D Mg alloy

\begin{tabular}{cccccccc}
\hline $\mathrm{Al}$ & $\mathrm{Zn}$ & $\mathrm{Mn}$ & $\mathrm{Si}$ & $\mathrm{Cu}$ & $\mathrm{Ni}$ & Other & $\mathrm{Mg}$ \\
\hline $8.3-9.7$ & $0.35-1$ & 0.15 & 0.1 & 0.03 & 0.002 & 0.02 & Balance \\
\hline
\end{tabular}

Among these techniques friction stir processing (FSP) has emerged as an alternative and improved method for creating densified and homogenized ultrafine grained bulk materials. Robson et al. [7] have shown the grain refinement as well as the dissolution of $\beta$-phase $\left(\mathrm{Mg}_{17} \mathrm{Al}_{12}\right)$ from $\mathrm{Mg}$ - $\mathrm{Al}$ castings by using FSP. Cavaliere et al. [8] reported the grain refinement as well as improvement in tensile properties of FSPed magnesium alloy. Darras et al. [9] have found the grain refinement and homogenization of the microstructure through a single pass of FSP in AZ31 magnesium alloy. FSP is also found to be an effective technique in the removal of defects in the cast and forged components $[9,10]$. The characteristics of FSP such as ease in automation, cost-effectiveness, safe to the environment, low process time and deployment as a single step process, are attracting researchers to explore the scope of this process in the fabrication of ultrafine grained bulk materials.

FSP has shown a great potential in improving the overall performance and reliability of magnesium alloy castings due to dissolution of unwanted phases ( $\beta$-phase- $\mathrm{Mg}_{17} \mathrm{Al}_{12}$, in aluminium containing magnesium alloys), homogenization of solute distribution without the need for a separate heat treatment, refinement of the grain structure and closure of porosity $[11,12]$. It has been observed that these microstructural changes result in enhancement of various mechanical properties such as yield strength, ductility, hardness and fatigue strength of magnesium alloys. Nadammal et al. [12] reported an increase in strength of $\mathrm{Al}$ alloy without compromising its ductility by FSP which is not possible by other SPD technique. Lee et al. [13] showed an increase in micro-hardness and wear resistance of AZ91 Mg-alloy by FSP. Tutar et al. [14] found high fracture strength and hardness in friction stir spot welded Al-alloy. It was reported by Cavaliere et al. [15] that FSP of AZ91 Mg-alloy leads to improvement in room temperature strength and ductility along with an increase in fatigue resistance. Khayyamin et al. [16] have also shown that FSP helps in increasing strength and micro-hardness of AZ91 Mg-alloy.

AZ91-D is the most commonly used high strength magnesium alloy having better corrosion resistance and castability as compared to other magnesium alloys. Different researchers have discussed the effects of changing the process parameters on various mechanical properties like fatigue strength, hardness, yield strength, and also the wear resistance of FSPed Mg- -alloys [13, 16-18]. Besides these, there is a scarcity of work based on the optimization of process parameters of FSP for die-cast AZ91-D alloy. There are some key design factors in FSP viz. tool transverse speed, tool rotational speed, number of passes, load, tilt angle, tool profile. There are also some minor factors such as plunge time, dwell time, ambient temperature etc., which govern the microstructure and mechanical properties of processed material.

For optimization of FSP parameters, Taguchi orthogonal array is widely used by researchers, as it offers detailed analysis with a reduced number of experiments. This technique helps to sustain the quality of results and also lowers the cost of experimentation $[9$, $16]$.

In the present research work, FSP of AZ91-D magnesium alloy has been done to improve its ultimate tensile strength (UTS). Taguchi method (L9 orthogonal array) has been used to optimize the friction stir process parameters. A detailed study has been conducted to analyse the effect of process parameters on microstructure and micro-hardness of different regions of FSPed AZ91-D material.

\section{Materials and methods}

The present study has been carried out on pressure die cast $6 \mathrm{~mm}$ thick sheets of AZ91-D magnesium alloy. The AZ91-D alloy material has been purchased from M/S Farmex India Pvt. Ltd., India and the composition specified by the manufacturer is presented in Table 1. To confirm the composition of the material, energy-dispersive X-ray spectroscopy (EDS) analysis has been performed as shown in Fig. 2. The magnesium alloy sheets with dimensions of $130 \mathrm{~mm} \times 75 \mathrm{~mm}$ were processed on a digital readout (DRO) mounted vertical milling machine (BFW, model VF-1E). For FSP, the tool was made of HS-13 tool steel, with a pin length of $3.1 \mathrm{~mm}$ and a shoulder diameter of $17 \mathrm{~mm}$. The tool tilt angle was kept to $1^{\circ}$ for all the experiments and the actual tool profile as presented in Fig. 1. For uniform refinement of grains, all the consecutive passes performed in the FSP were precisely aligned over previous passes.

For the process parameters optimization, Taguchi method has been adopted in the present study. In this method, it is very important to select the levels of process parameters. Based on the previous studies available in FSP literature [9, 16-18, 20-23] and by using 

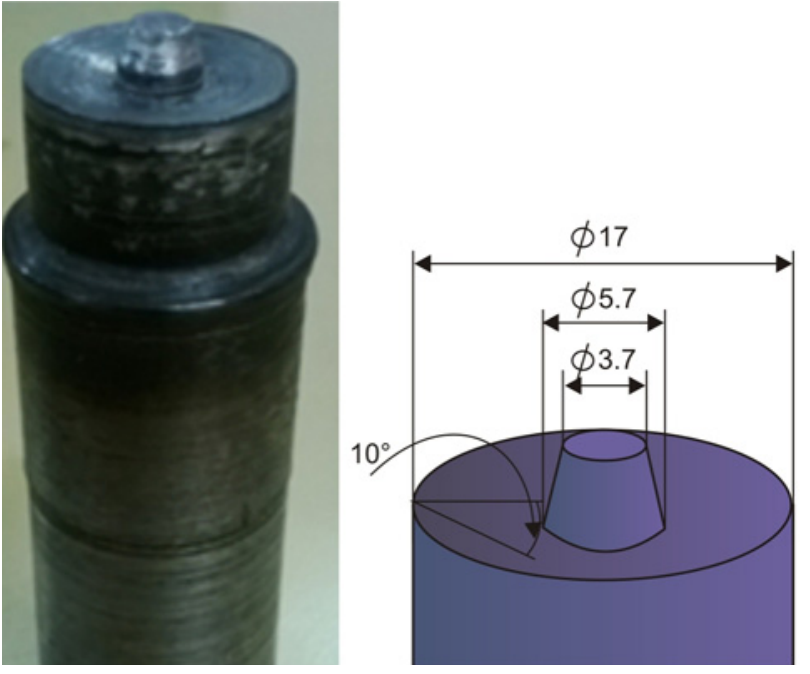

Fig. 1. Tool geometry used in the present study; (all dimensions in $\mathrm{mm}$ ).

best guess approach, the main process parameters and their levels were selected as shown in Table 2. Previous studies have shown that a significant grain refinement can be obtained with an increase in a number of passes in FSP of material [24-28]. For economical processing, it is very important to set the optimum number of passes for significant grain refinement. From best guess approach, the dwell time was selected as $27 \mathrm{~s}$ for $710 \mathrm{rpm}, 18 \mathrm{~s}$ for $1000 \mathrm{rpm}$ and $9 \mathrm{~s}$ for $1400 \mathrm{rpm}$ depending upon machine capability. The nomenclature of the specimens, which also indicates the different levels of process parameters as per Taguchi L-9 array is presented in Table 3. To make better data analysis for obtained ultimate tensile strength (UTS), signal-to-noise $(S / N)$ ratios are calculated to control the response variables as well as to reduce the experimental variability. There are three categories of the $S / N$ ratio, viz., smaller-the-better, larger-the-better, and nominal-the-best.

In the present study, the ultimate tensile strength (UTS) of processed material was selected as an objective function which is generally desired higher. In the present work, larger-the-better $S / N$ ratio has been used for data analysis, which is calculated according to the following equation:

$$
\left(\frac{S}{N}\right)_{\mathrm{LE}}=-10 \log \left(M S D_{\mathrm{LE}}\right),
$$

where

$$
M S D_{\mathrm{LE}}=\frac{1}{R} \sum_{j=1}^{R}\left(\frac{1}{y_{j}^{2}}\right),
$$

where $R$ is a number of replications $(R=3$, for the present study) and $y_{j}$ is the observed experimen-

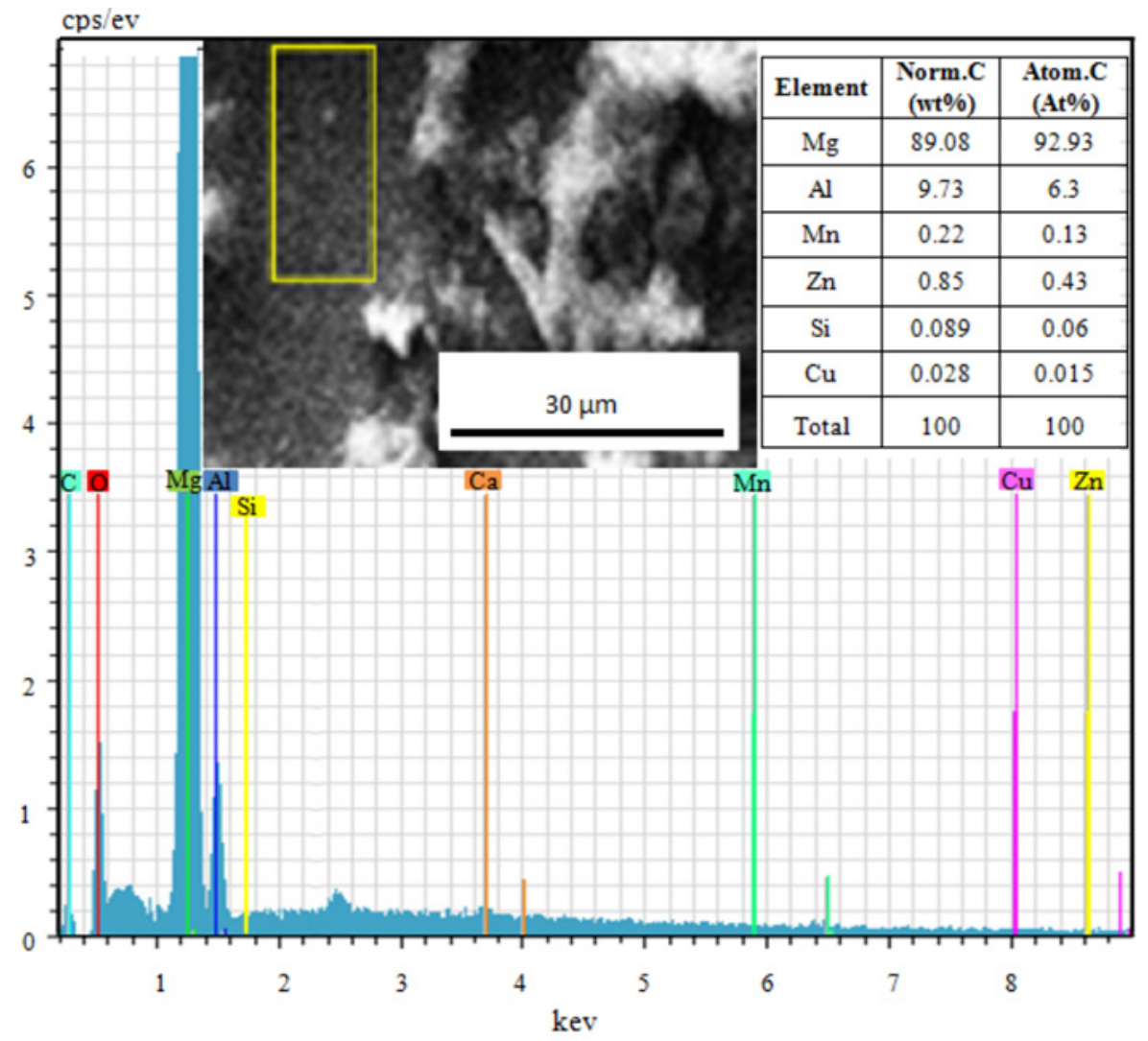

Fig. 2. EDS analysis of as-cast AZ91-D material. 
Table 2. Process parameters considered for optimization and their levels

\begin{tabular}{lcccc}
\hline Parameters & DOF( Levels-1) & Level 1 & Level 2 & Level 3 \\
\hline Rotational speed $(\mathrm{rpm})$ & 2 & 710 & 1000 & 1400 \\
Transverse speed $\left(\mathrm{mm} \mathrm{min}^{-1}\right)$ & 2 & 16 & 31.5 & 50 \\
Number of passes & 2 & 2 & 4 & 6 \\
Total DOF & 6 & & \\
\hline
\end{tabular}

Ta ble 3. Taguchi L-9 orthogonal array with the design parameters

\begin{tabular}{ccccc}
\hline $\begin{array}{c}\text { Nomenclature } \\
\text { of specimen }\end{array}$ & $\begin{array}{c}\text { Experiment } \\
\text { number }\end{array}$ & $\begin{array}{c}\text { Rotational speed } \\
(\mathrm{rpm})\end{array}$ & $\begin{array}{c}\text { Transverse speed } \\
\left(\mathrm{mm} \mathrm{min}^{-1}\right)\end{array}$ & $\begin{array}{c}\text { Number of } \\
\text { passes }\end{array}$ \\
\hline 111 & 1 & 710 & 16 & 2 \\
122 & 2 & 710 & 31.5 & 4 \\
133 & 3 & 710 & 50 & 6 \\
212 & 4 & 1000 & 16 & 4 \\
223 & 5 & 1000 & 51.5 & 6 \\
231 & 6 & 1000 & 16 & 6 \\
313 & 7 & 1400 & 31.5 & 2 \\
321 & 8 & 1400 & 50 & 4 \\
\hline
\end{tabular}

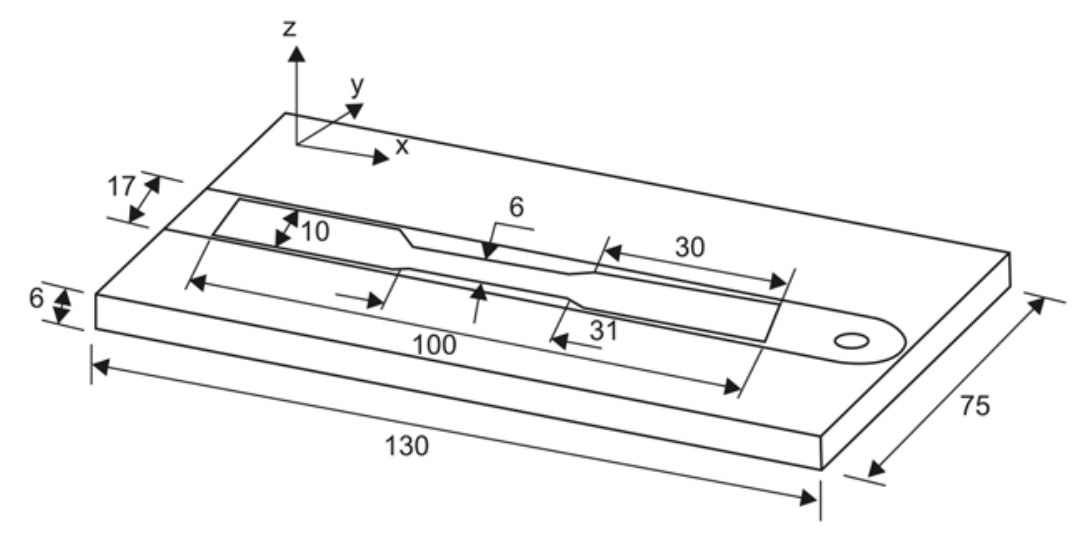

Fig. 3. UTS test specimen taken from FSPed region; (all dimensions in $\mathrm{mm}$ ).

tal data for $j_{\text {th }}$ performance characteristics. A higher $S / N$ ratio indicates superior consideration for ultimate tensile strength (UTS). To calculate the individual parameter effects, the following equation can be used:

$$
\frac{S}{N_{i j}}=\frac{1}{n} \sum_{k=1}^{n} \frac{S}{N_{k}},
$$

where $S / N_{i j}$ is the mean $S / N$ value of the $j$-th level of the $i$-th parameter, $n$ is the row number comprising a $j$-th level of the $i$-th parameter, and $S / N_{k}$ is the $S / N$ value of the $k$-th row.

After analysing the data by $S / N$ ratio, analysis of variance (ANOVA) was performed to calculate the percentage contribution of each process parameter to UTS of processed specimens. The sub-size specimens were prepared from the processed region as per the
ASTM-E8 standard, shown in Fig. 3. The details of specimens used for UTS testing are presented in Fig. 4. The specimens were tested at room temperature on a computerized universal testing machine (Instron-5980 ) with a strain rate of $10^{-2} \mathrm{~min}$.

Microstructure examination of the processed region has been carried out by scanning electron microscopy (SEM) and optical microscopy (OM). The cross-sectional specimens were prepared from the stir zone perpendicular to the direction of FSP. The specimens were ground and polished with different grades of emery papers, followed by cloth polishing for mirror finishing. After polishing, the samples were etched with an appropriate reagent consisting of acetic acid, $6 \mathrm{gm}$ picric acid, $10 \mathrm{ml}$ distilled water, $100 \mathrm{ml}$ ethanol, $5 \mathrm{ml} \mathrm{HCl}$ and $7 \mathrm{ml}$ nitric acid. Micro-hardness indents were taken along the depth and width of the stir 
Ta b le 4. Ultimate tensile strength (UTS) values and calculated $S / N$ ratios

\begin{tabular}{|c|c|c|c|c|c|c|c|}
\hline $\begin{array}{l}\text { Nomenclature } \\
\text { of specimen }\end{array}$ & $\begin{array}{l}\text { Experiment } \\
\text { number }\end{array}$ & $\begin{array}{l}\mathrm{UTS}_{1} \\
(\mathrm{MPa})\end{array}$ & $\begin{array}{l}\mathrm{UTS}_{2} \\
(\mathrm{MPa})\end{array}$ & $\begin{array}{l}\mathrm{UTS}_{3} \\
(\mathrm{MPa})\end{array}$ & $\begin{array}{l}\text { Average } \\
(\mathrm{MPa})\end{array}$ & $\begin{array}{l}\text { Standard deviation } \\
(\mathrm{MPa})\end{array}$ & $\begin{array}{l}S / N \\
\text { ratio }\end{array}$ \\
\hline 111 & 1 & 170.0 & 173.2 & 168.4 & 170.5 & 2.4 & 44.6 \\
\hline 122 & 2 & 145.8 & 148.0 & 146.1 & 146.6 & 1.2 & 43.3 \\
\hline 133 & 3 & 169.4 & 168.2 & 172.4 & 170.0 & 2.2 & 44.6 \\
\hline 212 & 4 & 159.7 & 153.1 & 156.2 & 156.3 & 3.3 & 43.9 \\
\hline 223 & 5 & 179.4 & 173.1 & 175.2 & 175.9 & 3.2 & 44.9 \\
\hline 231 & 6 & 179.4 & 193.6 & 170.5 & 181.2 & 11.7 & 45.1 \\
\hline 313 & 7 & 159.9 & 169.4 & 162.3 & 163.9 & 4.9 & 44.3 \\
\hline 321 & 8 & 160.1 & 150.9 & 163.2 & 158.1 & 6.4 & 44.0 \\
\hline 332 & 9 & 154.5 & 176.3 & 169.8 & 166.9 & 11.2 & 44.4 \\
\hline
\end{tabular}

Table 5 . Mean response table for the $S / N$ ratios of ultimate tensile strength

\begin{tabular}{lccc}
\hline Level & Rotational speed & Transverse speed & Number of passes \\
\hline 1 & 44.1887 & 44.2646 & 44.5741 \\
2 & $44.6353^{*}$ & 44.0630 & 43.8696 \\
3 & 44.2172 & $44.7136^{*}$ & $44.5976^{*}$ \\
Range & 0.4181 & 0.6506 & 0.7280 \\
Rank & 3 & 2 & 1 \\
\hline
\end{tabular}

*Optimum level

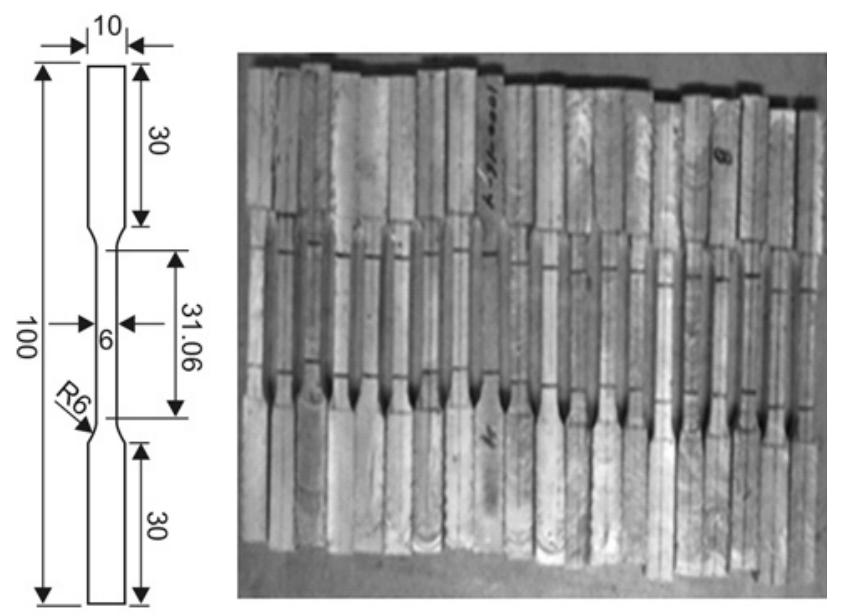

Fig. 4. Tensile strength sub-size specimens as per ASTM-E8 standard; (all dimensions in $\mathrm{mm}$ ).

zone. These indents were taken at an interval of $0.3 \mathrm{~mm}$ by using a digital micro-hardness tester (Omnitech G-419) under $100 \mathrm{gm}$ load, and $15 \mathrm{~s}$ dwell time.

\section{Results}

\subsection{Taguchi analysis and analysis of variance}

Using tensile tests, the UTS of FSP specimens pre- pared under different combinations of process parameters were calculated. The value of obtained UTS was taken as the response variable, and the corresponding $S / N$ ratios were calculated separately using Eq. (1) as shown in Table 4 . The mean $S / N$ ratios of the concerned process parameter were also calculated using Eq. (2) to determine the ranking of these process parameters as shown in Table 5. From the calculations, it was found that the influence of process parameters on UTS was in the order: a number of passes of FSP $>$ transverse speed $>$ rotational speed. The plots of the mean of means and mean of $S / N$ ratios were prepared as shown in Figs. 5a,b. The plots of main effects show how each process parameter affects the UTS of processed material. From a plot of the mean of means and mean of $S / N$ ratios, it is confirmed that both plots are giving the same conclusions about the effect of process parameters on UTS of processed material.

It is observed from the mean response - Table 5 , and the main effects plots - Figs. 5a and 5b that the highest values of response variable (UTS) can be obtained by keeping tool rotation speed to $1000 \mathrm{rpm}$ (medium value of rotational speed), feed to $50 \mathrm{~mm} \mathrm{~min}^{-1}$ (the highest value of transverse speed) and 6 number of passes (the highest value of number of passes). To confirm this optimum combination of process parameters, FSP has been performed. To predict the value of UTS ( $T_{\text {Predicted }}$ ) for obtained optimal combination Eq. (4) has been used: 

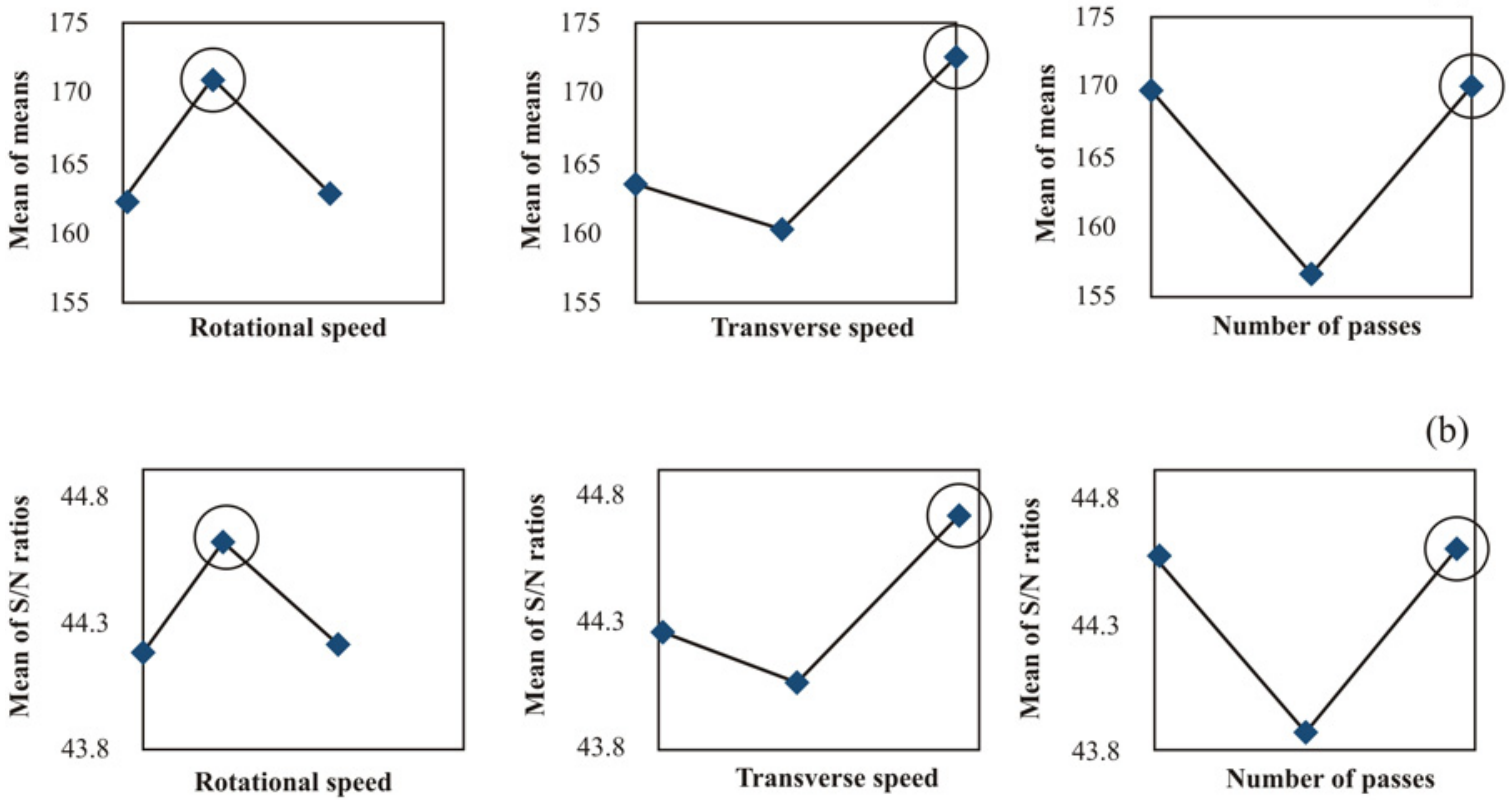

Fig. 5. (a) Main effects plot for the mean of means and (b) Main effects plot for a mean of $S / N$ ratios.

$$
T_{\text {Predicted }}=T_{\mathrm{m}}+\sum_{i=1}^{n}\left(T_{\mathrm{o}}-T_{\mathrm{m}}\right),
$$

where, for ultimate tensile strength (UTS), $T_{\mathrm{m}}$ is the mean response or mean $S / N$ ratio, $T_{\mathrm{o}}$ is the mean response at an optimal level, and $n$ is the number of main design parameters that affect the response characteristic. The Taguchi analysis had predicted an ultimate tensile strength of $182.76 \mathrm{MPa}$, but in confirmation test, the value of UTS was found to be 179.37 MPa, having an error of $1.85 \%$. A total increase of $24.56 \%$ in UTS of processed material has been observed against the UTS of parent material which was obtained as $144 \mathrm{MPa}$. From the stress-strain curves, Fig. 6, it can be seen that specimen-231 exhibits the highest strain of $4.64 \%$, but optimum specimen-233 has shown a strain of $3.67 \%$ which is $52.28 \%$ larger than parent material's strain $(2.41 \%)$.

ANOVA is a statistical tool used to find the significant factor. It helps in determining the percentage contribution of each design parameter to the response variable as well as in confirmation of significant design parameters. It also gives an idea of interactions by comparing the mean square against the estimated experimental errors at a specific confidence level [14]. To determine the relative contribution of different process parameters, the standard ANOVA procedure was performed using the $S / N$ ratios of UTS observations reported in L9 array. According to the ANOVA, the order of influence of process parameters on UTS of friction stir processed AZ91-D specimen is: the number of passes of FSP $>$ transverse speed $>$ rotational

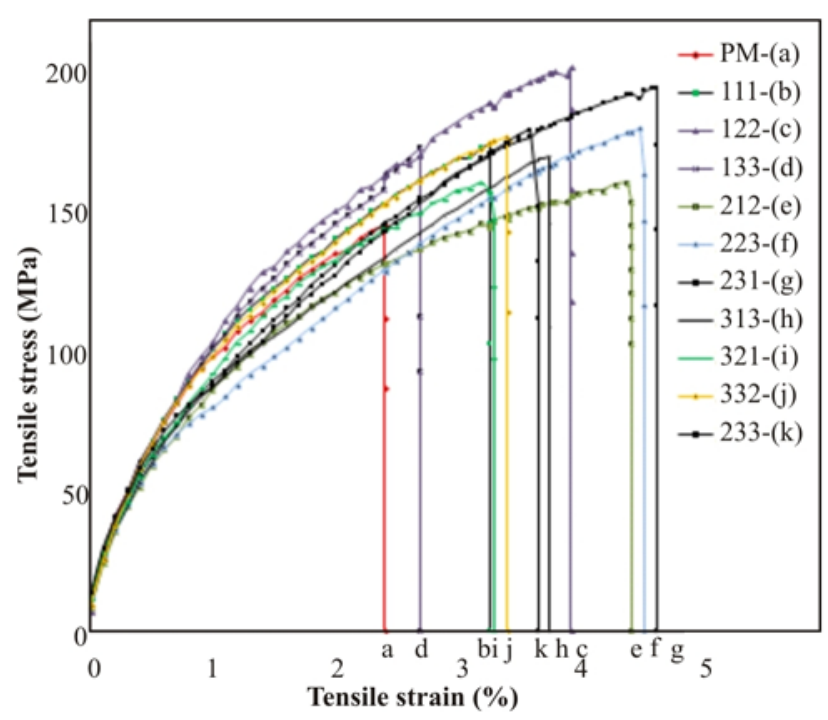

Fig. 6. Stress-strain curves for nine specimens, parent material and confirmation specimen.

speed as shown in Table 6. The result of ANOVA summary is in good agreement with that of the result of $S / N$ ratios presented in Table 5 . Also, the $F$-test was carried out to study the statistical significance of the process parameters. This analysis was carried out at a confidence level of $95 \%$. From the ANOVA summary Table 6 , it is evident that the $F$-values of rotational speed, transverse speed and the number of passes are all less than the critical $F$-value $(F 0.05,2,2=19)$. Thus, it can be concluded that all these treatments corresponding to different process parameters are not 
Table 6. ANOVA summary for means of the ultimate tensile strength

\begin{tabular}{lcccccc}
\hline Source & DOF & SS & MS & $F$-value & $F$-critical & Contribution (\%) \\
\hline Rotational speed & 2 & 0.3751 & 0.1875 & 0.8892 & 19 & 15.1 \\
Transverse speed & 2 & 0.6655 & 0.3327 & 1.5776 & 19 & 26.7 \\
Number of passes & 2 & 1.0269 & 0.5135 & 2.4346 & 19 & 41.3 \\
Error & 2 & 0.4218 & 0.2109 & & & 16.9 \\
Total & 8 & 2.4892 & & & & 100 \\
\hline
\end{tabular}
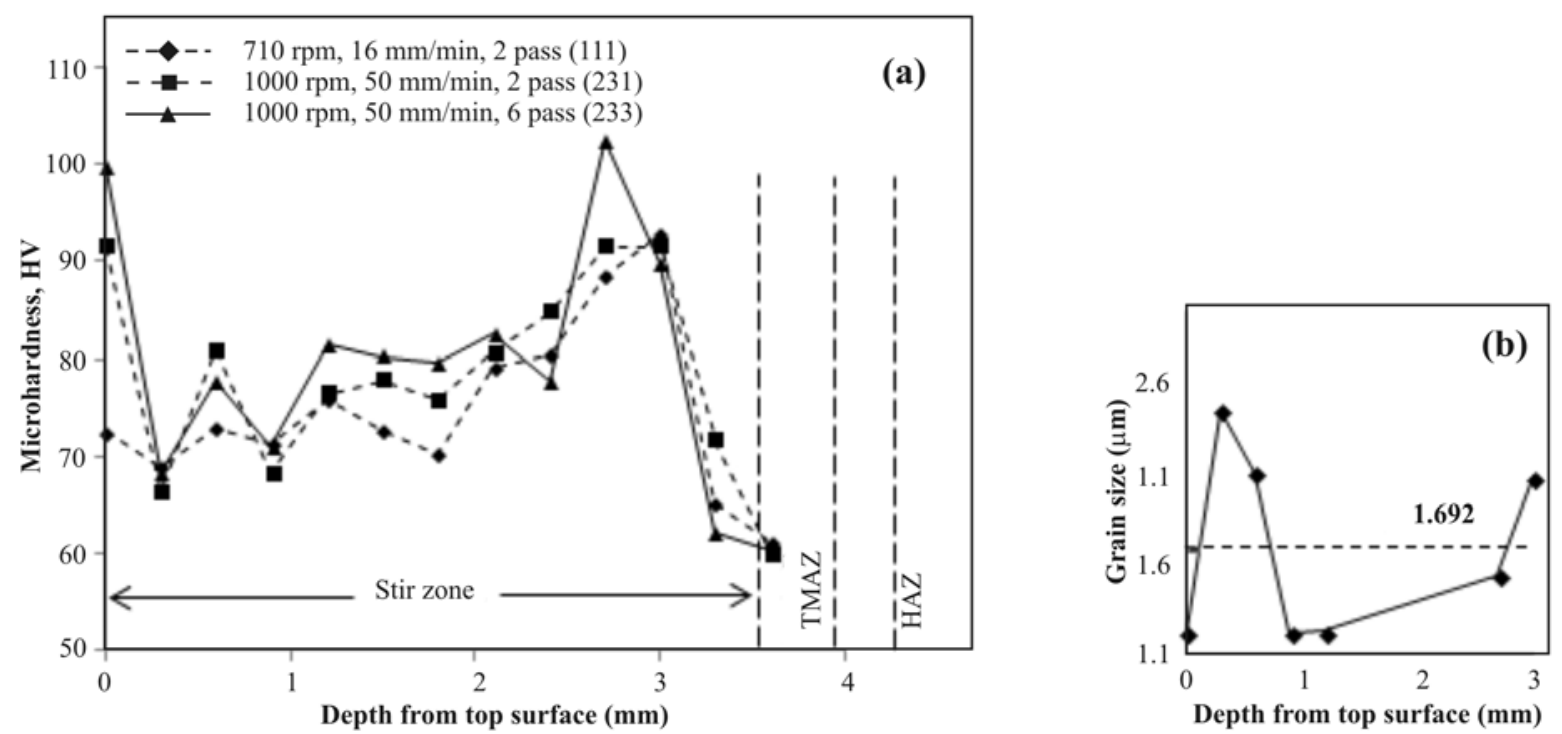

Fig. 7. (a) Micro-hardness profiles for the specimen-111, specimen-231, and specimen-233 along the depth of stir zone and (b) grain size variation along the depth of SZ in specimen-233.

significantly different. The interactions among the process parameters are not studied in present research work.

\subsection{Micro-hardness and microstructural studies}

Depending upon the UTS results, the samples having the maximum (sample-231), minimum (sample111), and optimum (sample-233) UTS were selected for micro-hardness tests. Figure 7a shows the microhardness values of the FSPed samples along the depth of the stir zone for three different sets of process parameters. Figure $8 \mathrm{a}$ shows the micro-hardness curve plotted for optimum FSPed sample-233 along the width of the stir zone at a depth of $2.7 \mathrm{~mm}$ from the top surface. In this study the average micro-hardness values along the depth of stir zone were obtained as $74.7 \mathrm{HV}, 78.2 \mathrm{HV}$ and $79.4 \mathrm{HV}$ for sample-111, sample231 and sample-233, respectively.

Figure 9a shows the optical micrograph of PM and Fig. 9b shows the SEM image of PM in which $\alpha$-phase (greyish structure having a major contribution in microstructure) and the $\beta$-phase- $\mathrm{Mg}_{17} \mathrm{Al}_{12}$ (whitish structures shown by arrows) can be iden- tified. The $\beta$-phase shown by the arrows is an aluminium rich coarse eutectic phase, and its continuous network is distributed on the grain boundaries of $\alpha$ phase. The average grain size of PM is about $10.78 \mu \mathrm{m}$ which has been reduced to 1.69 and $1.44 \mu \mathrm{m}$ in optimal specimen-233 along the depth and width of stir zone, respectively. The grain sizes obtained along the depth of stir zone for sample-111 and sample-231 were found to be 1.92 and $2.52 \mu \mathrm{m}$, respectively. For the optimally processed specimen-233, the variation in average grain size along the depth (Fig. 7b) and width (Fig. 8b) of stir zone was evaluated through image analysis technique using Image $\mathrm{J}$ (by NIH Image) freeware.

\section{Discussion}

\subsection{Increase in strength and ductility through FSP}

From Fig. 6, it can be observed that the UTS and \% elongation of FSPed specimens is improved as compared to PM. For the optimized FSPed specimen, the main reasons for the simultaneous increase in strength 

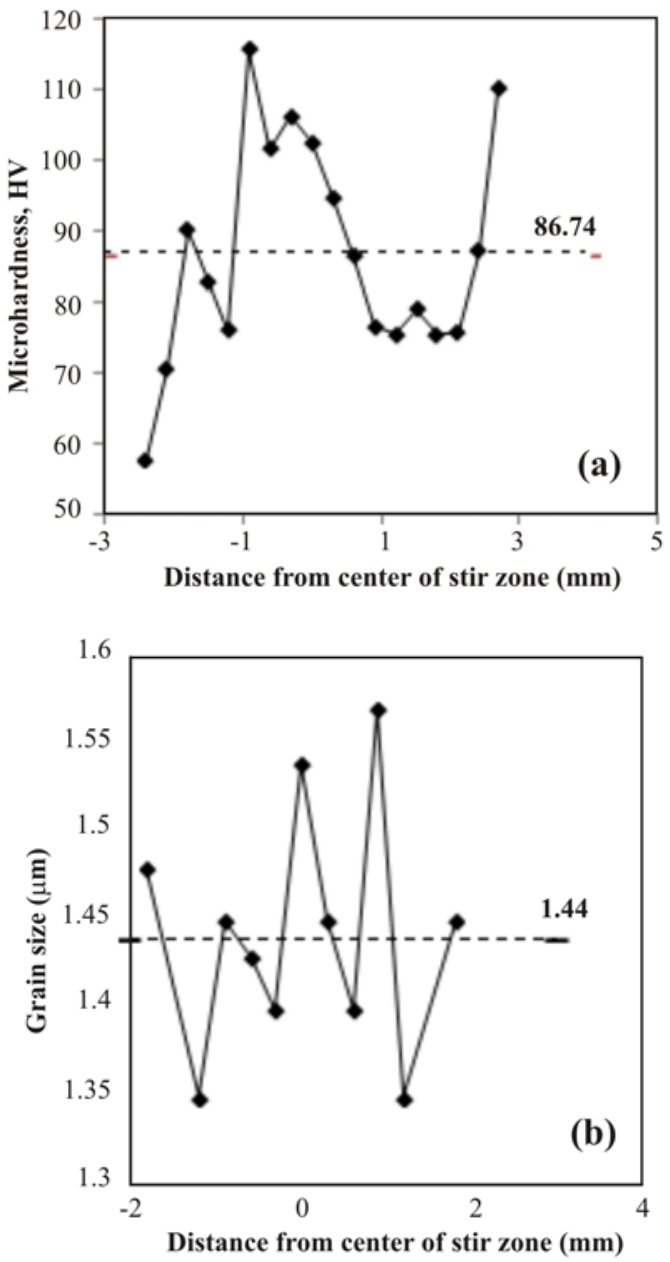

Fig. 8. (a) Micro-hardness profile and (b) grain size variation along the width of SZ in optimized FSPed specimen233.

and ductility (in terms of $\%$ elongation) may be as follows:

1. The casting defects, such as voids and porosities in cast AZ91-D alloy, have been removed due to FSP; thus favourable sites for crack generation and propagation have been reduced [19], and therefore \% elongation is increased.

2. A continuous network of $\beta$-phase in the grain boundaries which are the favourable sites for crack propagation has been dissolved by FSP $[16,21]$ leading to enhanced $\%$ elongation.

3. Ultra-grain refinement as shown in Fig. 10, obtained from 6 passes of FSP increases the density of grain boundaries. This leads to more obstacles to dislocation movement and crack propagation, which results in an appreciable increase in the strength of FSPed material [11, 16, 22].

Because of the dynamic recrystallization in FSP [1], the coarse $\alpha$-grains of PM as shown in Figs. 9a,b are significantly refined into equiaxed grains result-
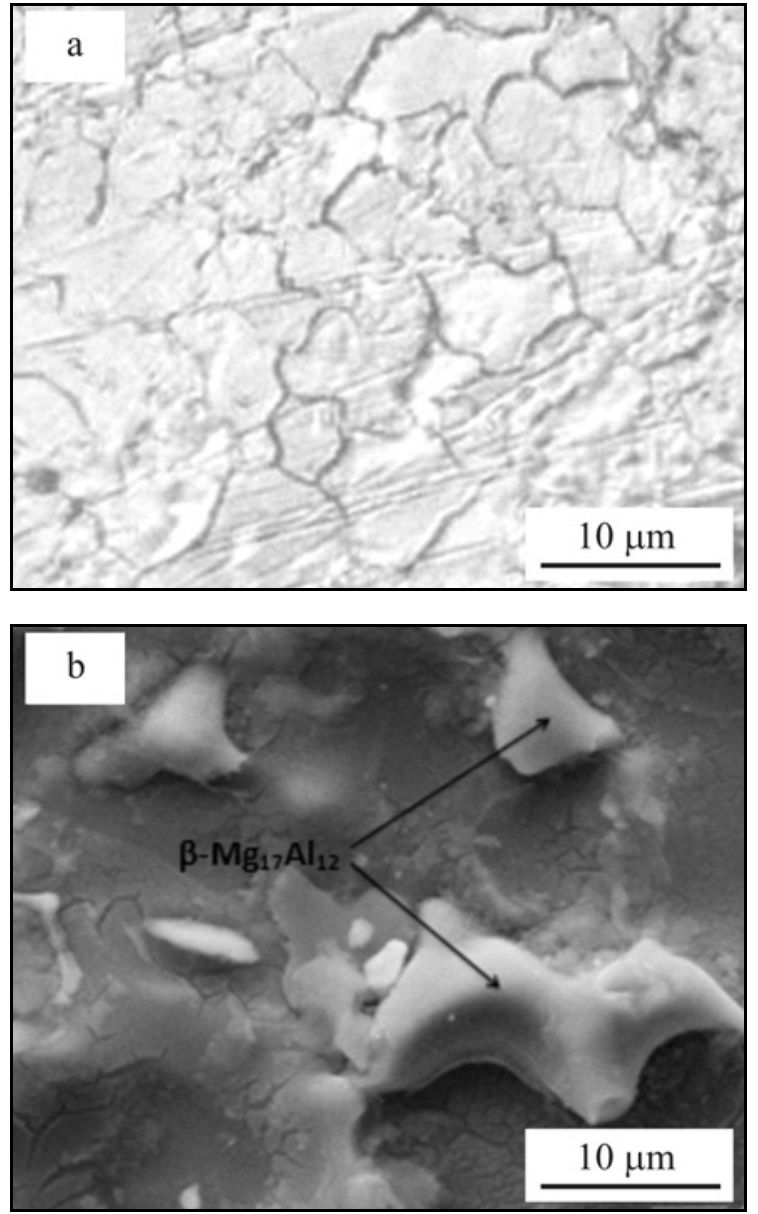

Fig. 9. (a) OM image showing the microstructure of PM and (b) SEM image showing the $\beta$-phase in parent AZ91-D material.

ing in a significant improvement in UTS and microhardness of material [20]. The grain refinement can be confirmed by analysing the optical micrographs of all the samples processed through different combinations of parameters, as shown in Figs. 10a-c. As a result of sufficient temperature rise due to friction along with severe plastic deformation, the initial coarse $\beta$-phase in PM is significantly reduced and dissolved [21], as shown in Fig. 11b-d. The dissolution of $\beta$-phase has also resulted in improved properties of optimized FSPed specimen. As a result of multiple passes of FSP, increased dislocation density impedes dislocation movement, and thus dislocation-dislocation interaction improves the mechanical properties [11, 22].

\subsection{Increase in micro-hardness}

The hardness variations (Fig. 7a) for sample-111, sample-231, and sample-233 along the depth can be explained on the basis of severe plastic deformation and the peak temperature generated at different depths. At the top surface, the hardness values 

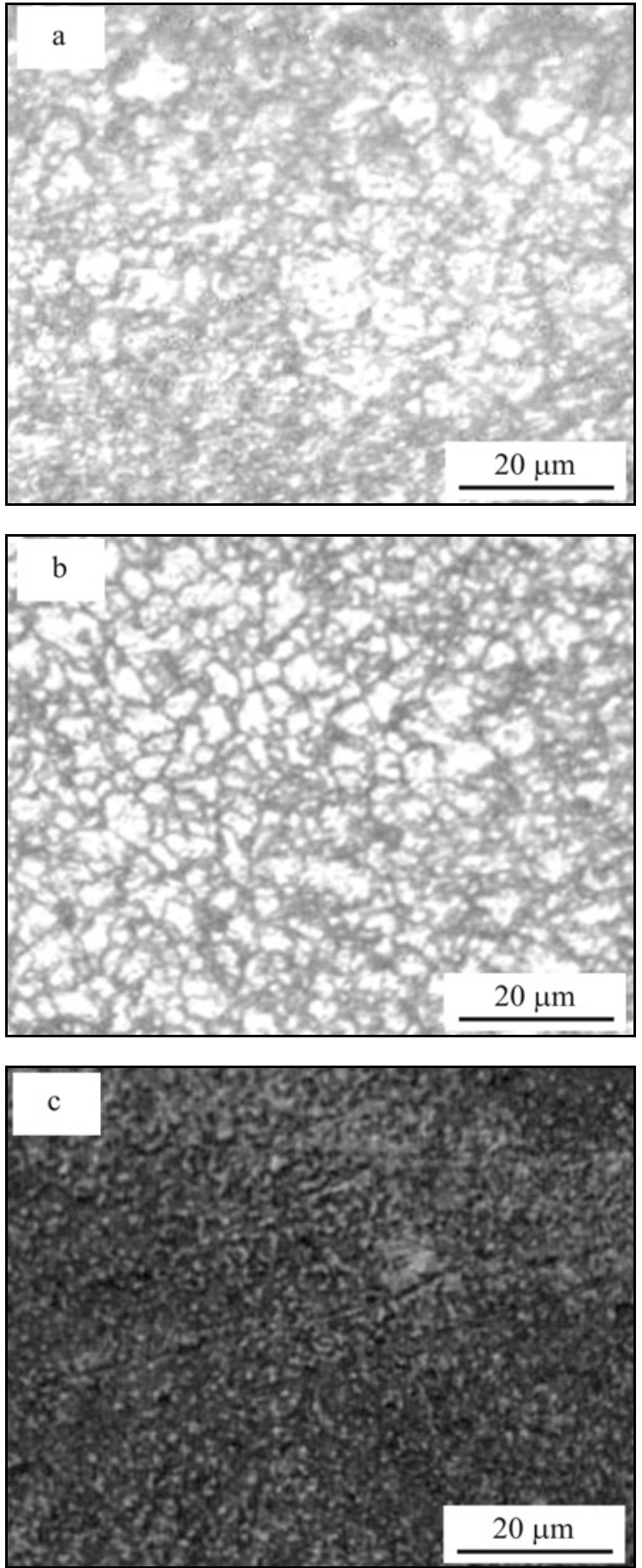

Fig. 10. (a) OM image of SZ of specimen-111, (b) OM image of SZ of specimen-231, and (c) OM image of SZ of specimen-233.

are high in the region of flow arm, where the grain size is small as the stirring effect dominates the thermal softening $[27,28]$. As the temperature decreases from the surface to the bottom, the grain size decreases due to dynamic recrystallization and thus increase in micro-hardness value is observed as shown in Fig. 7b. In the interface region of TMAZ and HAZ as shown in Fig. 7a, it was found that the micro-hardness value drops to $60 \mathrm{HV}$ which is even lesser than the average micro-hardness value (i.e. $65 \mathrm{HV}$ ) of parent material (PM) which indicates that grain growth has taken place due to thermal softening effect as a result of sufficient rise in temperature along the width of SZ [19]. For the sample-233, the average micro-hardness value along the width of $\mathrm{SZ}$ was obtained as $86.7 \pm 15.05 \mathrm{HV}$, and average grain size was found to be $1.44 \pm 0.07 \mu \mathrm{m}$. The variations in these micro-hardness and grain size values in SZ are small which indicates that the multi-pass FSP with optimum process parameters have well dispersed the $\beta$-phase and also refined the grain size to a large extent as compared to single-pass FSP.

\section{Challenges and future scope}

Optimized FSP results in significant improvement in grain refinement and mechanical properties. The tensile results show that FSP can be used as a technique for obtaining a simultaneous increase in strength and ductility. Various studies have shown that FSP is an effective tool for obtaining high strain rate superplasticity (HSRS) in magnesium alloys [29, 30], so further research can be carried out to analyse the effect of FSP parameters on HSRS of AZ91-D. Due to the process similarity, same optimized process parameters for FSP can be used for FSW of AZ91-D. The current level of the optimized number of passes is large, so further research is required to further develop this process to reduce the number of passes. This can be accomplished by using submerged friction stir processing where grain growth due to frictional heat is comparatively less as compared to normal FSP [31, 32]. The other technique employing an abrasive tool probe instead of a threaded tool probe can be used to obtain more refined and homogeneous microstructure through FSP. As the current study reveals the number of passes of FSP is the most influencing factor as compared to tool rotational and transverse speed. Therefore multi-pass FSP with same parameters can be used for the fabrication of particles reinforced magnesium matrix composites (MMCs).

\section{Conclusions}

In the present investigation, the friction stir processing parameters have been optimized for AZ91-D magnesium alloy to improve its ultimate tensile strength by using the Taguchi L9 orthogonal array. The main conclusions can be summarized as follows:

1. Taguchi method is very effective for optimization of FSP parameters. The optimal combination of FSP 

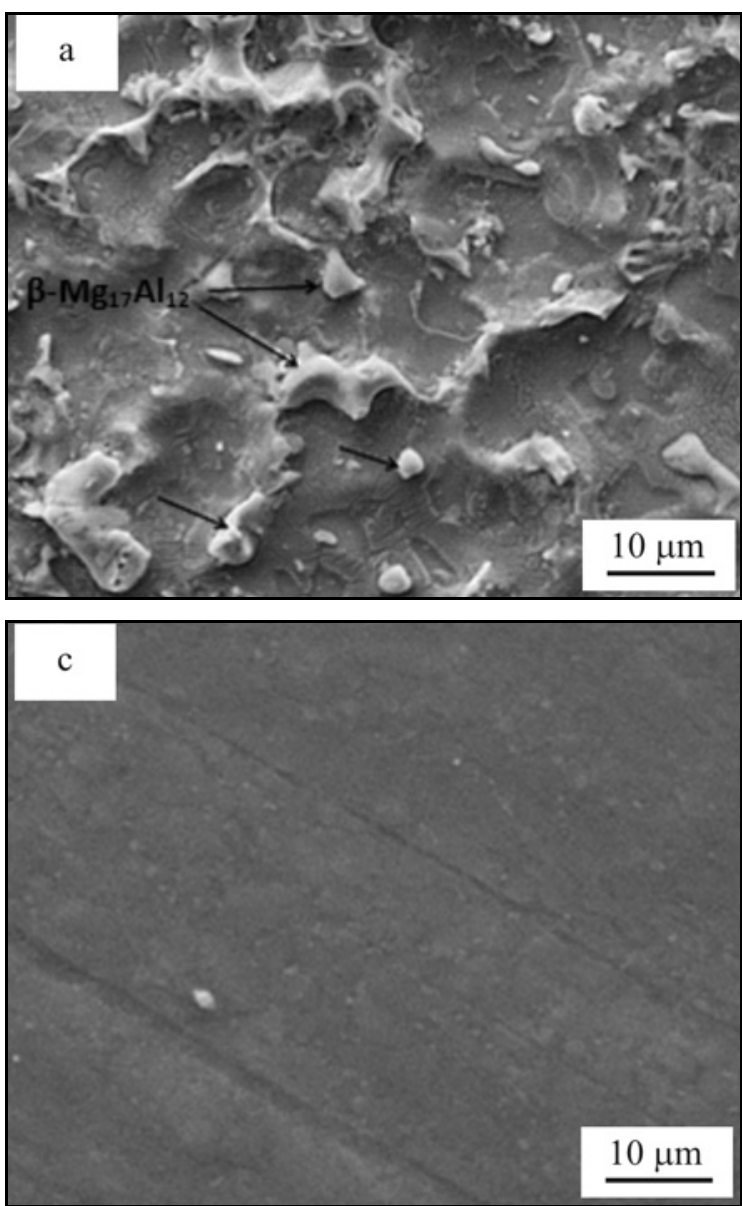

Fig. 11. SEM images of: (a) PM, (b) SZ of specimen-111, (c) SZ of specimen-231, and (d) SZ of specimen-233. parameters resulted in increased UTS and \% elongation of AZ91-D magnesium alloy.

2. The order of importance of the process parameters was the number of passes followed by transverse speed and tool rotational speed. A number of passes of FSP was statistically found as the most significant factor.

3. The ultrafine-grained structure due to dynamic recrystallization and uniform distribution of $\beta$-phase in FSPed material resulted in increased UTS and \% elongation.

4. With the increase in a number of passes of FSP, more equiaxed and uniformly refined grains were obtained and consequently, the micro-hardness in SZ is increased. Maximum micro-hardness was obtained for the optimized process parameters at $2.7 \mathrm{~mm}$ below the top surface of the processed region. The minimum micro-hardness was found in the interface region of TMAZ and HAZ, below the full penetration depth of tooltip.

5. By increasing the transverse speed, the material becomes less susceptible to frictional heat generated during FSP. This results in the reduction of grain size in SZ leading to improvement in UTS of FSPed material. However, an increase in rotational
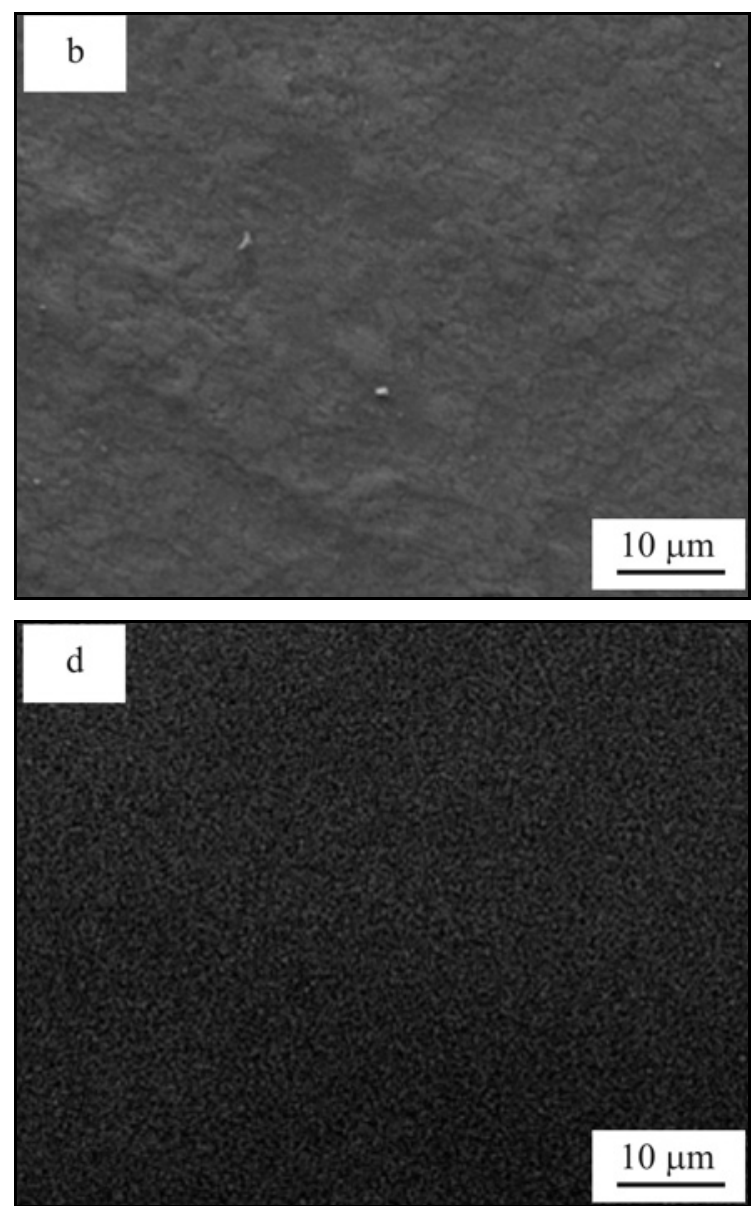

speed led to more frictional heat generation and more grain growth and decreased UTS. Similarly, very low rotational speed results in tunnel defect which also reduces the UTS. So a moderate value of rotational speed is required to enhance the properties of parent material.

\section{Acknowledgements}

The authors gratefully acknowledge the Welding Research Laboratory, IIT Roorkee, Roorkee, India, for providing mechanical and metallurgical test facilities. Authors would also like to thank Director, Wadia Institute of Himalayan Geology, Dehradun, India, for providing the SEM and EDS facilities.

\section{References}

[1] Fattah-Alhosseini, A., Sabaghi Joni, M.: Journal of Alloys and Compounds, 646, 2015, p. 685. doi:10.1016/j.jallcom.2015.06.181

[2]. Samaee, J. Z. M., Najafi, S., Eivani, A. R., Jafarian, H. R.: Mater. Sci. Eng. A, 669, 2016, p. 350. doi:10.1016/j.msea.2016.05.070 
[3] Sadawy, M. M.. Ghanem, M.: Def. Technol., 12, 2016, p. 316. doi:10.1016/i.dt.2016.01.013

[4] Fattah-Alhosseini, A., Naseri, M., Alemi, M. H.: J. Manuf. Process., 22, 2016, p. 120. doi:10.1016/j.jmapro.2016.03.006

[5] Omid, S., Fattah-Alhosseini, A., Mazaheri, Y.: J. Manuf. Process., 22, 2016, p. 269. doi:10.1016/j.jmapro.2016.03.015

[6] Saito, Y., Utsunomiya, H., Tsuji, N., Sakai, T.: Acta Materialia, 47, 1999, p. 579. doi:10.1016/S1359-6454(98)00365-6

[7] Robson, J. D., Cui, S., Chen, Z. W.: Mater. Sci. Eng. A, 527, 2010, p. 7299. doi:10.1016/j.msea.2010.07.093

[8] Cavaliere, P., De Marco, P. P.: Mater. Sci. Eng. A, 462, 2007, p. 393. doi:10.1016/j.msea.2006.04.150

[9] Darras, B. M., Khraisheh, M. K., Abu-Farha, F. K., Omar, M. A.: J. Mater. Process. Technol., 191, 2007, p. 77. doi:10.1016/i.jmatprotec.2007.03.045

[10] Cavaliere, P., De Marco, P. P.: Mater. Charact., 58, 2007, p. 226. doi:10.1016/j.matchar.2006.04.025

[11] Li, W. Y., Fu, T., Hütsch, L., Hilgert, J., Wang, F. F., dos Santos, J. F., Huber, N.: Mater. Des., 64, 2014, p. 714. doi:10.1016/i.matdes.2014.07.023

[12] Nadammal, N., Kailas, S. V., Suwas, S.: Mater. Des., 65, 2015, p. 127. doi:10.1016/j.matdes.2014.09.005

[13] Lee, W. B., Lee, C. Y., Kim, M. K., Il Yoon, J., Kim, Y. J., Yoen, Y. M., Jung, S. B.: Compos. Sci. Technol., 66, 2006, p. 1513. doi:10.1016/i.compscitech.2005.11.023

[14] Tutar, M., Aydin, H., Yuce, C., Yavuz, N., Bayram, A.: Mater. Des., 63, 2014, p. 789. doi:10.1016/j.matdes.2014.07.003

[15] Cavaliere, P., De Marco, P. P.: Mater. Charact., 58, 2007, p. 226. doi:10.1016/j.matchar.2006.04.025

[16] Khayyamin, D., Mostafapour, A., Keshmiri, R.: Mater. Sci. Eng. A, 559, 2013, p. 217. doi:10.1016/j.msea.2012.08.084

[17] Asadi, P., Givi, M. K. B., Abrinia, K., Taherishargh, M., Salekrostam, R.: J. Mater. Eng. Perform., 20, 2011, p. 1554. doi:10.1007/s11665-011-9855-x

[18] Salehi, M., Farnoush, H., Aghazadeh, J.: Mater. Des., 63, 2014, p. 419. doi:10.1016/j.matdes.2014.06.013
[19] Cavaliere, P., De Marco, P. P.: J. Mater. Process. Technol., 184, 2007, p. 77. doi:10.1016/j.jmatprotec.2006.11.005

[20] Zhang, D., Wang, S., Qiu, C., Zhang, W.: Mater. Sci. Eng. A, 556, 2012, p. 100. doi:10.1016/j.msea.2012.06.063

[21] Feng, A. H., Ma, Z. Y.: Scr. Mater., 56, 2007, p. 397. doi:10.1016/j.scriptamat.2006.10.035

[22] Babu, N. K., Kallip, K., Leparoux, M., Alogab, K. A., Maeder, X., Arroyo, Y., Dasilva, R.: Mater. Des., 95, 2016, p. 534. doi:10.1016/j.matdes.2016.01.138

[23] Afrin, N., Chen, D. L., Cao, X., Jahazi, M.: Mater. Sci. Eng. A, 472, 2008, p. 179. doi:10.1016/i.msea.2007.03.018

[24] Khodabakhshi, F., Simchi, A., Kokabi, A. H., Nosko, M., Simančík, F., Švec P.: Mater. Sci. Eng. A, 605, 2014, p. 108. doi:10.1016/j.msea.2014.03.008

[25] Chowdhury, S. M., Chen, D. L., Bhole, S. D., Cao, X.: Mater. Sci. Eng. A, 527, 2010, p. 6064. doi:10.1016/j.msea.2010.06.012

[26] Ferguson, J. B., Sheykh-Jaberi, F., Kim, C., Rohatgi, P. K., Cho, K.: Mater. Sci. Eng. A, 558, 2012, p. 193. doi:10.1016/i.msea.2012.07.111

[27] Barmouz, M., Besharati Givi, M. K., Seyfi, J.: Mater. Charact., 62, 2011, p. 108. doi:10.1016/j.matchar.2010.11.005

[28] Mishra, R. S., Mahoney, M. W. (Eds): Friction Stir Welding and Processing. Materials Park, ASM International 2007. doi:10.1361/fswp2007p001

[29] Zhang, D., Wang, S., Qiu, C., Zhang, W.: Mater. Sci. Eng. A, 556, 2012, p. 100. doi:10.1016/j.msea.2012.06.063

[30] Chai, F., Zhang, D., Zhang, W., Li, Y.: Mater. Sci. Eng. A, 590, 2014, p. 80. doi:10.1016/j.msea.2013.10.029

[31] Xue, P., Xiao, B. L., Ma, Z. Y.: J. Mater. Sci. Technol., 29, 2013, p. 1111. doi:10.1016/j.jmst.2013.09.021

[32] Chai, F., Zhang, D., Li, Y., Zhang, W.: Mater. Sci. Eng. A, 568, 2013, p. 40. doi:10.1016/j.msea.2013.01.026 